\title{
ALTERAÇÕES MORFOLÓGICAS EM Eichhornia crassipes (AGUAPÉ) (Mart.) Solms-Laubach (PONTEDERIACEAE), EXPOSTA A ELEVADAS CONCENTRAÇÕES DE MERCÚRIO
}

\author{
PATRÍCIALUÍSA DE ARAÚJO MENDES* \\ SYLVIA THERESE MEYER** \\ IGOR ALEXIS DE SOUZA NORONHA***

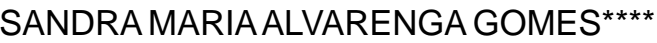 \\ MÉRCIA HELENA DOS SANTOS ${ }^{\star \star \star \star \star ~}$
}

\begin{abstract}
Este trabalho teve como objetivo verificar as possíveis alterações morfológicas causadas em Eichhornia crassipes (aguapé) por mercúrio, avaliando-se os efeitos tóxicos desse metal sobre o crescimento dessa espécie. Os experimentos tiveram duração de cinco dias, em frascos escuros contendo 0,5 L de solução de Hoagland e Arnon (1950), com $1 / 4$ da força iônica original e pH 6,5, acrescida de diferentes concentrações de nitrato de mercúrio dihidratado $\left[\mathrm{Hg}\left(\mathrm{NO}_{3}\right)_{2} .2 \mathrm{H}_{2} \mathrm{O}\right]: 0,5 ; 2,5 ; 5,0$ e 10,0 mg L-1, sendo cada tratamento realizado em triplicata. Os indivíduos de todos os tratamentos, exceto o tratamento controle, apresentaram sintomas visuais de toxidez, observandose, cloroses, enrugamento e enrolamento da lâmina foliar e necroses. Os resultados mostraram que a proporção de injúrias aumentou com a elevação da concentração do metal em solução. A produção da biomassa possivelmente foi afetada pelas dosagens de mercúrio, causando redução na ordem de $5,4 \%, 9,2 \%, 9,0 \%$ e $14,2 \%$ para as doses de 0,5; 2,5; 5,0 e 10,0 $\mathrm{mg} \mathrm{L}^{-1}$ de mercúrio, respectivamente. Já os indivíduos controle aumentaram a massa fresca em $9,0 \%$, aproximadamente. As lesões foliares observadas até o término do ensaio não ocasionaram a morte de nenhum dos indivíduos. Sugere-se que sejam desenvolvidos estudos anatômicos, fisiológicos e químicos para a obtenção de dados que poderão evidenciar o potencial fitorremediador dessa espécie a fim de ser futuramente utilizada e recomendada para a remoção de mercúrio em ambientes aquáticos.
\end{abstract}

PALAVRAS-CHAVE: ALTERAÇÕES MORFOLÓGICAS; MERCÚRIO; Eichhornia crassipes; FITORREMEDIAÇÃO.

* Bióloga, Mestranda em Botânica, Departamento de Biologia Vegetal, Universidade Federal de Viçosa (UFV), Viçosa, MG (e-mail: mendes.botanica@gmail.com).

** Bióloga, Doutora, Pesquisadora, Setor de Recursos da Terra, Fundação Centro Tecnológico de Minas Gerais (CETEC), Belo Horizonte, MG (e-mail: sylvia.meyer@cetec.br).

*** Biólogo, Pós-Graduando Lato Senso em Plantas Ornamentais e Paisagismo, Universidade Federal de Lavras, Lavras, MG (e-mail: igorbionoronha@yahoo.com.br)

*** Bióloga, Doutora, Professora Adjunta, Universidade Federal Rural de Pernambuco, Serra Talhada, PE (e-mail: sandragomes@uast.ufrpe.br).

***** Química, Pesquisadora, Setor de Biotecnologia e Tecnologia Química, CETEC, Belo Horizonte, MG (email: mercia.santos@cetec.br). 


\section{INTRODUÇÃO}

Tendo em vista a sua extrema toxicidade e persistência no ambiente, além de acarretar sérios impactos negativos não somente às comunidades biológicas integrantes desses ecossistemas, mas também à saúde humana, a poluição por mercúrio em ambientes aquáticos constitui preocupação crescente.

São vários os relatos sobre acidentes causados por contaminação de mercúrio. $\mathrm{Na}$ década de 50 no Japão, nas cidades de Niigata e Minamata, 1.073 pessoas foram contaminadas por mercúrio em decorrência da ingestão de peixes contaminados, sendo que 657 delas morreram. No Iraque, em 1971/72, cerca de 6.000 pessoas foram afetadas por se alimentarem de cereais tratados à base de mercúrio e, aproximadamente, 500 morreram. No Brasil, citam-se os exemplos da contaminação por mercúrio em Pernambuco envolvendo o rio Botafogo até o estuário e o Canal de Santa Cruz, afetando a biota aquática e comprometendo o consumo humano. O derramamento da lixívia negra, em 1976, contaminou o rio Mogi-Guaçu, causando a mortandade de peixes e o comprometimento da represa Barra Bonita, muito importante na atividade pesqueira que também teve suas águas comprometidas pelo mercúrio (EYSINK e MORAES, 1998).

O mercúrio constitui um dos metais mais tóxicos, não tendo função biológica conhecida (CURSINO et al., 2003). Quando liberado no meio aquático, pode sofrer o processo de biomagnificação dos produtos para os consumidores e quanto mais longa a cadeia trófica, maior será a concentração acumulada (RODRIGUES et al., 2003).

As fontes potenciais de mercúrio são resultantes de efluentes industriais, queima de lixo, fundições e garimpos (LEMOS et al. 1998; ESTEVES, 1998), exploração mineral e refino do metal, fábricas de cloro-álcali, indústrias de polpa e papel, indústrias de plástico e eletrônica, práticas agrícolas, hospitais e indústrias de medicamentos de mercúrio (AZEVEDO, 2003). No Brasil, o garimpo de ouro ainda representa a maior fonte de emissão de mercúrio e desde a época colonial essa atividade vem degradando ecossistemas brasileiros (AZEVEDO, 2003).

Nas últimas duas décadas, o garimpo de ouro na região norte do Brasil pode ter liberado três mil toneladas de mercúrio para o meio ambiente, gerando grave contaminação (AZEVEDO, 2003). Estima-se que na Região Amazônica, onde estão localizadas as principais jazidas de ouro do Brasil, $62 \%$ do total de mercúrio utilizado nos processos de concentração e extração são lançados ao ambiente, correspondendo entre 70 a 170 ton/ ano (VIEIRA e PASSARELLI, 1996). Estima-se que para cada $450 \mathrm{~g}$ de ouro extraídos dos rios da Amazônia, o dobro é despejado em mercúrio. Nas áreas industriais, que utilizam mercúrio como matéria-prima, cerca de 10 mil toneladas/ ano de rejeitos de mercúrio são lançadas na biosfera (AZEVEDO, 2003).

Existem evidências de que todas as plantas contêm naturalmente quantidades traços de mercúrio, mesmo porque o referido metal ocorre naturalmente nos solos. Entretanto, a quantidade de mercúrio encontrada nos tecidos das plantas pode ser modificada pela ação antropogênica (BRITO, 1983).

O mercúrio resiste a processos naturais de degradação, podendo permanecer por muitos anos em ecossistemas aquáticos e terrestres sem perder sua toxicidade (AZEVEDO, 2003). Devido à ausência da cultura de reciclagem desse metal e o desconhecimento técnicooperacional de garimpos clandestinos, aliado ao custo relativamente baixo do metal líquido, grandes quantidades de mercúrio têm contaminado muitas áreas úmidas e ocasionado sérios prejuízos para todo o ecossistema (CETEC, 2001). 
O Conselho Nacional do Meio Ambiente (Resolução CONAMA nº 357, de 17 de março de 2005) estabeleceu para as águas doces de classes 1 e 3 o limite de 0,0002 e 0,002 mg/L de mercúrio, respectivamente. Os efluentes de qualquer fonte poluidora somente poderão ser lançados, direta ou indiretamente, nos corpos de água em níveis de 0,01 mg/L de mercúrio (BRASIL, 2005).

As plantas mais promissoras para serem utilizadas em mecanismos de diminuição das concentrações de poluentes em ambientes aquáticos são as macrófitas aquáticas, pois elas apresentam características como habilidade de acumular altas concentrações de metal, rápido crescimento e considerável estabilidade fisiológica, quando submetidas a altas concentrações. A planta boa acumuladora deve ser capaz de retirar os íons do metal do seu metabolismo, depositando-os no vacúolo, removendo-os por bombeamento da célula ou ainda transformando-os em formas inócuas (BRITO, 1983).

Algumas espécies vegetais aquáticas apresentam grande capacidade de concentrar metais pesados (BASSI e SHARMA, 1993; GAUR, NORAHO e CHAUHAN, 1994; POTT e POTT, 2002), podendo mesmo tolerar altas concentrações sem apresentar efeitos negativos no seu crescimento (MATAGI, SWAI e MUGABE, 1998). Particularmente, as macrófitas aquáticas flutuantes livres desempenham papel importante na absorção de metais, pois são capazes de captar materiais suspensos na água por meio de seu sistema radicular, antes que esses se depositem no sedimento (LEMOS et al., 1998; MATAGI, SWAI e MUGABE, 1998; WHO, 1989; BRITO, 1983). Essa capacidade é fundamental visto que o mercúrio em ambientes aquáticos liga-se, predominantemente, ao material em suspensão (MASCARENHAS et al., 2004). Assim, plantas aquáticas são importantes bioindicadoras de poluição e potenciais agentes descontaminantes de elementos-traço (BRITO, 1983; WHO, 1989).

Vários trabalhos têm sido conduzidos a fim de estudar a capacidade de macrófitas aquáticas para reter metais pesados de soluções poluídas e os mecanismos de tolerância aos poluentes (OLIVEIRA et al., 2001). A importância das macrófitas aquáticas foi amplamente discutida na literatura, sendo sua utilização como bioindicadora da qualidade da água em ambientes lóticos e lênticos uma das mais relevantes (PEDRALLI, 2003).

De maneira geral, os organismos refletem as características do ambiente em que vivem. Eichhornia crassipes tem apresentado bons resultados no tratamento de efluentes líquidos diversos, principalmente para esgotos sanitários e remoção de material particulado, sendo muitas vezes chamado de filtro natural, além de exercer ação filtrante e bioquímica. Suas características de alta multiplicação e facilidade de adaptação a ambientes diversos têm atraído a atenção para a avaliação do seu emprego na remoção de metais pesados, em baixas concentrações, presentes em efluentes líquidos (GRANATO, 1995). Estudos da NASA demonstraram, na década de 1970, sua capacidade de remoção de metais pesados, fenóis e outros componentes químicos em lagos de aguapé (SCHNEIDER e RUBIO, 2003).

Por muito tempo, Eichhornia crassipes foi considerado apenas como praga vegetal de lagos e represas. Depois essa espécie foi reconhecida como indicadora de poluição química pelo elevado potencial de extração de elementos-traço da água, acumulados nas raízes (BRITO, 1983).

As macrófitas aquáticas estão permanentemente expostas a níveis excessivos de elementos-traço, incluindo o mercúrio, uma vez que esse metal encontra-se em altas concentrações nos sedimentos (AZEVEDO, 2003). Nesse sentido, a fitorremediação constitui alternativa promissora pela capacidade de determinadas espécies de macrófitas aquáticas, incluindo Eichhornia crassipes, de bioacumular e/ou detectar poluentes (NEDELKOSKA e 
DORAN, 2000). Surge, portanto, a necessidade de investigar as possíveis alterações morfológicas nessa espécie exposta a níveis excessivos de mercúrio, visando sua utilização em monitoramento ambiental. Todavia, não se encontrou estudos morfológicos sobre o acúmulo e a toxicidade do mercúrio em E. crassipes.

O principal objetivo desta proposta foi verificar as possíveis alterações morfológicas causadas em Eichhornia crassipes (aguapé) por mercúrio, na forma de nitrato de mercúrio dihidratado $\left[\mathrm{Hg}\left(\mathrm{NO}_{3}\right)_{2} .2 \mathrm{H}_{2} \mathrm{O}\right]$, avaliando-se os efeitos tóxicos desse metal sobre 0 crescimento dessa espécie. Pretendeu-se também estudar o comportamento de $E$. crassipes exposta ao mercúrio e verificar as concentrações de mercúrio toleradas por essa espécie.

\section{MATERIAL E MÉTODOS}

\subsection{OBTENÇÃO DAS PLANTAS}

As plantas aquáticas da espécie Eichhornia crassipes foram coletadas na Fundação Zoo-Botânica de Belo Horizonte (MG) Jardim Botânico por tratar-se de ambiente isento de poluente residual

químico. Após a coleta, as amostras foram lavadas em água corrente e transferidas para recipientes de polietileno com capacidade de $5 \mathrm{~L}$, contendo solução nutritiva de HOLGLAND e ARNON (1950), 1/4 da força iônica original, e acondicionadas em sala de crescimento da Fundação Centro Tecnológico de Minas Gerais (CETEC).

No início dos ensaios, foram selecionados indivíduos homogêneos quanto ao tamanho, aspectos das folhas e raízes e peso fresco. Em seguida, foram lavados em água corrente, mantidos por 24 horas em água desmineralizada e transferidos para recipientes de polietileno com solução nutritiva de HOAGLAND e ARNON (1950), com 1/4 da força iônica original e $\mathrm{pH} 6,5$. As plantas foram mantidas em sala de crescimento com temperatura e luminosidade controladas $\left(25 \pm 2^{\circ} \mathrm{C}, 230 \mu \mathrm{E} \mathrm{s}^{-1} \mathrm{~m}^{-2}\right)$, sob fotoperíodo de 16 horas, na qual permaneceram por três dias para adaptação às condições experimentais.

\subsection{EXPOSIÇÃO DAS PLANTAS AO MERCÚRIO}

Adotou-se experimento inteiramente casualizado, com três repetições para cada concentração de mercúrio. Após o período de adaptação de três dias, o peso inicial da matéria fresca foi aferido, e as plantas divididas em parcelas experimentais da seguinte forma: tratamento controle, cujas plantas permaneceram em solução nutritiva apenas; e quatro grupos de tratamento, cuja solução nutritiva foi acrescida de quatro concentrações diferentes de nitrato de mercúrio dihidratado $\left[\mathrm{Hg}\left(\mathrm{NO}_{3}\right)_{2} .2 \mathrm{H}_{2} \mathrm{O}\right]: 0,5 ; 2,5 ; 5,0$ e 10,0 mg L-1 tratamentos I, II, III e IV, respectivamente (em triplicata).

As plantas foram colocadas em frascos escuros contendo $0,5 \mathrm{~L}$ de solução de HOAGLAND e ARNON (1950), acrescida do metal com $1 / 4$ da força iônica original e pH 6,5 e acondicionadas em sala de crescimento do CETEC, nas mesmas condições anteriormente citadas. Os indivíduos foram expostos ao nitrato de mercúrio dihidratado por cinco dias. $\mathrm{O}$ pH foi corrigido para 6,5 a cada dois dias e o volume da solução completado, diariamente, com solução de Hoagland e Arnon a fim de compensar a perda de volume de água por absorção, transpiração e evaporação (AKSORN e VISOOTTIVISETH, 2004). 
No quinto dia, a partir do início dos tratamentos, as plantas foram retiradas dos vasos e lavadas com solução de ácido nítrico 1\% para remoção do mercúrio adsorvido à superfície das raízes e folhas. Após a lavagem, aferiu-se o peso fresco de cada um dos indivíduos a fim de quantificar o ganho ou perda de massa fresca durante o experimento.

\subsection{SINTOMATOLOGIA DOS INDIVÍDUOS DE E. crassipes EXPOSTOS AO Hg}

Foram realizados registros fotográficos das plantas expostas às diferentes concentrações de mercúrio no primeiro, terceiro e quinto dia do experimento, utilizando-se câmera digital Sony cyber-shot DSC-W70 7.2 mega pixels.

As injúrias observadas nos indivíduos foram descritas segundo os autores CHAVES et al. (2002), SILVA et al. (2000) e FORNASIERO (2003).

\section{RESULTADOS E DISCUSSÃO}

\subsection{AVALIAÇÃO DO CRESCIMENTO DE Eichhornia crassipes}

Os indivíduos de E. crassipes quando expostos ao nitrato de mercúrio dihidratado $\left[\mathrm{Hg}\left(\mathrm{NO}_{3}\right)_{2} .2 \mathrm{H}_{2} \mathrm{O}\right]$ apresentaram perda de massa fresca ao final do experimento. Nos indivíduos do tratamento controle verificou-se ganho de massa. A produção da biomassa foi possivelmente afetada pelas dosagens de mercúrio, causando redução na ordem de 5,4\%, $9,2 \%, 9,0 \%$ e $14,2 \%$ para as doses de 0,$5 ; 2,5 ; 5,0$ e $10,0 \mathrm{mg} \mathrm{L}^{-1}$ de mercúrio, respectivamente. Já os indivíduos controle aumentaram a massa fresca em 9,0\%, aproximadamente (Figura 1).

\section{FIGURA 1 - PESO FRESCO EM GRAMAS DE E. crassipes NO CONTROLE E NOS TRATAMENTOS EM CINCO DIAS DE EXPERIMENTO}

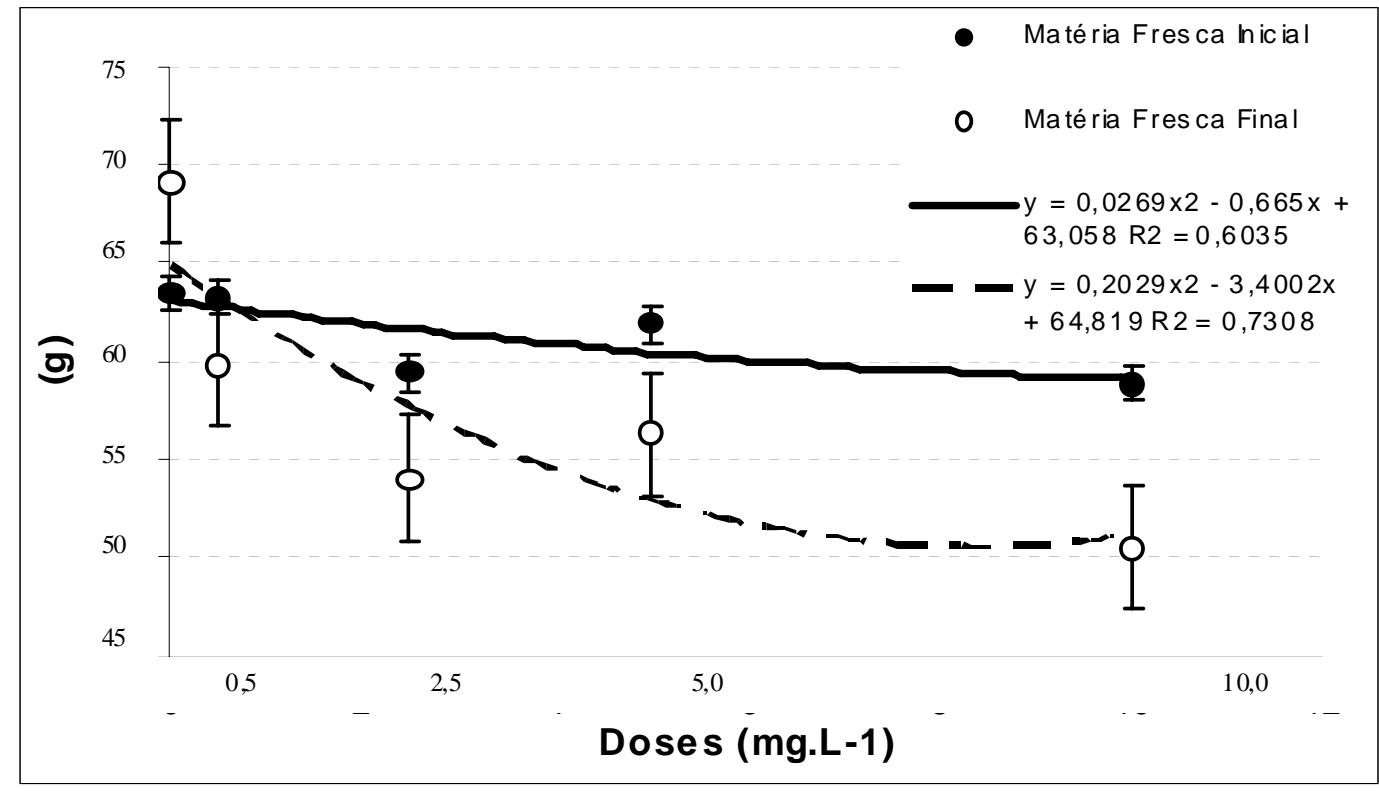


Segundo OLIVEIRA et al. (2001) plantas de aguapé, quando submetidas à exposição de cádmio, também apresentaram queda na taxa de crescimento. Conforme discutem esses autores, a exposição de plantas ao cádmio em níveis tóxicos durante períodos de tempo relativamente longos (cinco dias ou mais) resulta, quase sempre, em forte interferência sobre o crescimento das plantas.

ALVES et al. (2003), em estudos realizados com E. crassipes submetida ao cobre em níveis excessivos, verificaram alterações no desenvolvimento dos indivíduos, ou seja, o cobre foi indutor de estresse nessa espécie. Provavelmente, o mercúrio também foi determinante para a perda da massa fresca observada no presente estudo.

No estudo de GUIMARÃES (2006), as espécies Salvinia minima e Azzola caroliniana expostas a diferentes concentrações de arsênio apresentaram ganho de massa fresca ao longo do período experimental. A elevação da concentração de As na solução provoca redução no crescimento das plantas. S. mínima, quando exposta à solução de $5,0 \mathrm{mg} \mathrm{L}^{-1}$ de $A s$, não apresentou crescimento e $A$. caroliniana quando exposta à concentração de $0,5 \mathrm{mg} \mathrm{L}^{-1}$ de $A s$ mostrou crescimento igual ao grupo controle.

\subsection{SINTOMATOLOGIA DOS INDIVÍDUOS DE E. crassipes EXPOSTOS AO MERCÚRIO}

Não foram observadas alterações morfológicas para os indivíduos controle, ou seja, as plantas que não foram submetidas à adição de mercúrio permaneceram sadias durante todo o ensaio.

Os indivíduos de todos os tratamentos com mercúrio apresentaram sintomas visuais de toxidez, porém não houve morte de nenhum dos indivíduos ao término do ensaio. As injúrias identificadas nas margens das lâminas foliares de $E$. crassipes foram caracterizadas como clorose, início de necrose e necrose. Nos pecíolos e lâminas foliares observou-se desidratação com consequente enrolamento e enrugamento.

Conforme a concentração de mercúrio em solução foi aumentada, registrou-se maior proporção de injúrias nas plantas. Dessa forma, o grau de injúria provocado pelo mercúrio varia de acordo com a concentração em cada tratamento.

Os indivíduos do tratamento I sofreram leves injúrias, embora tenham apresentado sintomatologia desde o segundo dia de exposição ao mercúrio como clorose, início de necrose, desidratação seguida de enrugamento e enrolamento da lâmina foliar. Os indivíduos do tratamento II apresentaram a seguinte sintomatologia desde o segundo dia de exposição ao mercúrio: desidratação do pecíolo e da lâmina foliar, seguida de enrolamento e enrugamento, cloroses e necroses.

Os indivíduos dos tratamentos III e IV foram os mais afetados, sendo as injúrias observadas desde o segundo dia de exposição ao mercúrio. Os indivíduos do tratamento III apresentaram desidratação da lâmina foliar e pecíolos, ocorrendo enrugamento e enrolamento das folhas, cloroses e necroses extensas ao final do ensaio. Os indivíduos do tratamento IV apresentaram folhas desidratadas, seguidas de enrolamento e enrugamento da lâmina foliar, cloroses, necroses e desidratação de pecíolos ao final do experimento (Figura 2).

Injúrias como clorose e necrose nas margens das lâminas foliares também foram os principais sintomas observados em outras monocotiledôneas submetidas à poluição por fluoretos na atmosfera (WEINSTEIN, 1977; CONOVER e POOLE, 1982; SUN e SU, 
1985; ARNDT, FLORES e WEINSTEIN, 1995). No estudo de CHAVES et al. (2002), Panicum maximum apresentou amarelamento, clorose e necrose nas lâminas foliares e em Chloris gayana foi registrado enrugamento das folhas como sintomas de toxidez ao flúor.

\section{FIGURA 2 - SINTOMATOLOGIA DOS INDIVÍDUOS DE Eichhornia crassipes EXPOSTOS AO MERCÚRIO EM CINCO DIAS DE TRATAMENTO}

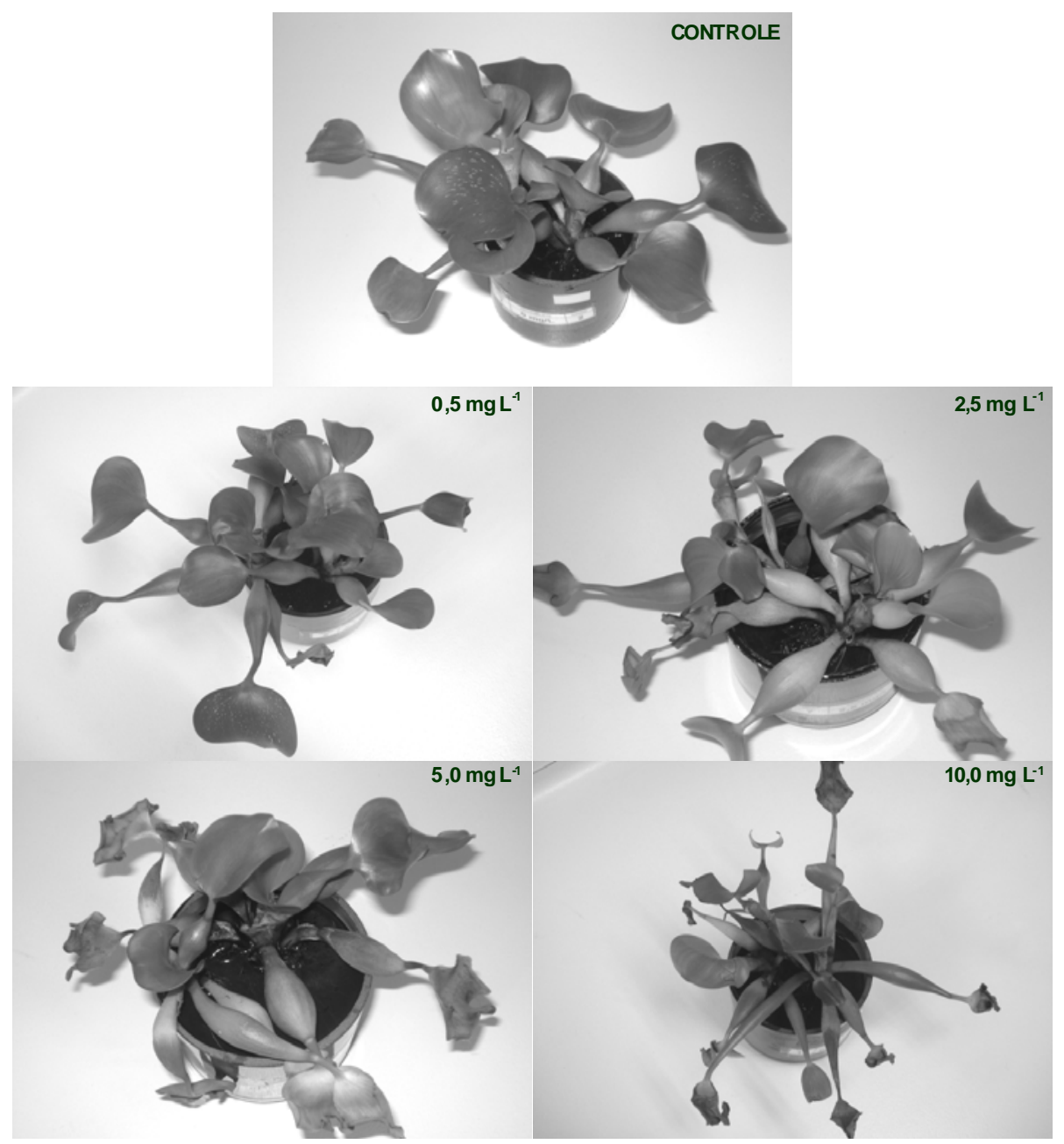

SILVA et al. (2000) em estudos utilizando flúor em chuva simulada apontou Spondias dulcis como a espécie com potencial bioindicador pelos fortes sintomas apresentados de necroses e cloroses no ápice e margem das lâminas foliares. FORNASIERO (2003) indicou, como principais injúrias em Hypericum perforatum sob os efeitos de flúor, necroses pontuais ao longo da lâmina foliar.

Spirodela polyrhiza e Azolla pinnata são apontadas, no estudo de GAUR, NORAHO e CHAUHAN (1994), como resistentes em diferentes graus aos metais $\mathrm{Cd}, \mathrm{Cr}$, Co, $\mathrm{Ni}$ e $\mathrm{Pb}$. Segundo GARG e CHANDRA (1990), Ceratophyllum demersum sobrevive em ambientes com concentrações de $\mathrm{Cr}$ maiores que os recomendados e apresenta grande habilidade para acumular esse metal. De acordo com AMARAL e BITTRICH (2002), Salvinia spp. apresenta grande capacidade de remover e acumular metais pesados, como o $\mathrm{Pb}$ e $\mathrm{Cd}$. 
No trabalho de CLARK et al. (1981), Lemna perpusilla mostrou-se importante para a depuração de ambientes contaminados em função de sua grande capacidade de acumular os metais $\mathrm{Cd}, \mathrm{Zn}, \mathrm{Cu}, \mathrm{Fe}, \mathrm{Mn}, \mathrm{Cr}$, Pb, Ni. Investigações realizadas por PFEIFFER et al. (1986) indicaram que a espécie $E$. crassipes pode ser utilizada como boa monitora biológica da contaminação por metais, sugerindo que possa ser utilizada em programas de biomonitoramento de mercúrio. Entretanto, conforme os resultados do presente estudo, há limitação do uso de E. crassipes na remediação de ambientes aquáticos altamente impactados, uma vez que altas concentrações de mercúrio em solução prejudicaram seu desenvolvimento. GRANATO (1995) apontou a espécie E. crassipes para ser empregada na despoluição de ambientes aquáticos, devido às suas capacidades depurativas.

\title{
4 CONCLUSÃO
}

Quando exposta a concentrações elevadas de mercúrio, a espécie E. crassipes apresentou diminuição do ganho de massa fresca, além de evidenciar sintomatologia típica de toxicidade ao metal em solução, como cloroses, enrugamento, enrolamento da lâmina foliar e necroses.

Os indivíduos avaliados neste estudo apresentaram sensibilidade em presença de mercúrio, sendo que a proporção de injúrias aumentou com a elevação da concentração do metal.

Sugere-se que sejam desenvolvidos estudos anatômicos, fisiológicos e químicos para a obtenção de dados que poderão evidenciar o potencial fitorremediador dessa espécie a fim de ser futuramente utilizada e recomendada para a remoção de mercúrio em ambientes aquáticos.

A implementação de estudos visando à indicação de espécies de macrófitas como bioindicadoras e despoluidoras de águas é recomendável em termos de pesquisas limnológicas, botânicas e ecológicas. A interdisciplinaridade e a integração de dados físicos, químicos e biológicos são imprescindíveis para a identificação de outras espécies de macrófitas aquáticas que apresentem as características de absorção de elementos-traço, devendo, portanto, ser estimulados projetos dessa natureza.

\begin{abstract}
MORPHOLOGIC ALTERATIONS IN Eichhornia crassipes (WATER HYACINTH) (Mart.) Solms-Laubach, DISPLAYED TO RAISED MERCURY CONCENTRATIONS

The objective of this work is to verify the possible morphologic changes observed in Eichhornia crassipes (water hyacinths) due to mercury, evaluating the toxic effects of this metal on the development of this species. The experiments were carried out during five days in dark bottles with 0,5 L of Hoagland and Arnon (1950) solution, with $1 / 4$ of the original ionic force and $\mathrm{pH} 6.5$, added of different levels of concentration of dihydrated mercury nitrate $\left[\mathrm{Hg}\left(\mathrm{NO}_{3}\right)_{2} .2 \mathrm{H}_{2} \mathrm{O}\right]: 0.5 ; 2.5 ; 5.0$ e $10.0 \mathrm{mg} \mathrm{L}^{-1}$, being each treatment carried out in triplicates. All treated individuals, except those of the control treatment, presented visual symptoms of toxicity and chlorosis, wrinkling and rolling up of the foliar blade and necrosis. The results showed that the higher the concentration of the metal in the solution the higher the proportion of injuries. The production of biomass was possibly affected by dosages of mercury, decreasing $5.4 \%, 9.2 \%, 9.0 \%$ and $14.2 \%$ when the doses of mercury were $0.5 ; 2.5 ; 5.0$ and $10.0 \mathrm{mg} \mathrm{L}^{-1}$ respectively. Whereas the new mass of treatment control individuals increased $9.0 \%$, approximately. The foliar injuries were not mortal until the ending of this experiment. It is suggested the development of anatomical physiological and chemical studies for the obtention of data that could make evident the phytoremediator potential of this species in order to be used and recommended for the removal of the mercury in aquatic environments.
\end{abstract}




\section{REFERÊNCIAS}

1 AKSORN, E.; VISOOTTIVISETH, P. Selection of suitable emergent plants for removal of arsenic from arsenic contamined water. Science Asia, v. 30, p. 105-113, 2004.

2 AlVES, E.; CARDOSO, L.R.; SCAVRONI, J. L. R.; FERREIRA, L. C.; BOARO, C. S. F; CATANEO, A. C. Avaliações fisiológicas e bioquímicas de plantas de aguapé (Eichhornia crassipes) cultivadas com níveis excessivos de nutrientes. Planta Daninha, Viçosa, v. 21, p. 27-35, 2003.

3 AMARAL, M. C. E.; BITTRICH, V. Laguinhos: mini-ecossitemas para escolas e jardins. Ribeirão Preto: Holos, 2002. 89 p.

4 ARNDT, U.; FLORES, F.; WEINSTEIN, L. Efeitos do flúor sobre as plantas: diagnose de danos na vegetação do Brasil. Porto Alegre: Ed. UFRGS, 1995.

5 AZEVEDO, F. A. Toxicologia do mercúrio. São Carlos/SP: Editora RiMa, 2003. 272 p.

6 BASSI, R.; SHARMA, S.S. Changes in proline content accompanying the uptake of zinc and copper by Lemna minor. Annals of Botany, v. 72, p.151-154, 1993.

7 BRASIL. Conselho Nacional do Meio Ambiente. Resolução CONAMA n. 357, de 17 de março de 2005. Dispõe sobre a classificação dos corpos de água e diretrizes ambientais para o seu enquadramento, bem como estabelece as condições e padrões de lançamento de efluentes, e dá outras providências. Disponível em: www.mma.gov.br/port/conama/res/res05/res35705. Acesso em: 15 ago. 2007.

8 BRITO, I.C. A importância dos bioindicadores vegetais no ambiente aéreo, aquático e terrestre - plantas indicadoras do mercúrio. In: CONGRESSO NACIONAL DE BOTÂNICA, 34., 1983, Porto Alegre. Anais... Porto Alegre: SBB/UFRGS, 1983. p. 115-119.

9 CETEC. Fundação Centro Tecnológico de Minas Gerais. Desenvolvimento de tecnologia para descontaminação de áreas degradadas pela atividade garimpeira, com recuperação de mercúrio e ouro (Estudo de Caso - Córrego Ricol Paracatu-MG). Belo Horizonte, 2001. 60 p. (Relatório Técnico).

10 CLARK, J. R.; VANHASSEL, J. H.; NICHOLSON, R. B.; CHERRY, D. S.; CAIRNS, J. Jr. Accumulation and depuration of metals by duckweed (Lemna perpusilla). Ecotoxicology and Environmental Safety, v. 5, p. 87-96, 1981.

11 CHAVES, A. L. F.; SILVA, E. A. M.; AZEVEDO, A. A.; OLIVA, M. A.; MATSOUKA, K. Ação do flúor dissolvido em chuva simulada sobre a estrutura foliar de Panicum maximum Jacq (colonião) e Chloris gayana Kunt. (capim-Rhodes) - Poaceae. Acta Botânica Brasílica, v. 16, p. 395-406, 2002.

12 CONOVER, C.A.; POOLE, R.T. Fluoride induced chlorosis and necrosis of Dracaena fragrans "massaangeana". J. Amer. Soc. Hort. Sci., v. 107, n.1, p. 136-139, 1982.

13 CURSINO, L.; MATTOS, S.V.M.; SILVA, N.O.; CHARTONE-SOUZA, E.; NASCIMENTO, A.M.A. Measurement of volatilized mercury by a mini-system: a simple, reliable and reproducible technique. Brasilian Archives of Biology and Technology, v. 46, n. 4, p. 731-734, 2003.

14 ESTEVES, F.A. Fundamentos de limnologia. 2. ed. Rio de Janeiro: Interciência, 1998. 602 p.

15 EYSINK, G.G.J.; MORAES, R.P. Recuperação de áreas degradadas: subsídios para manejo e recuperação de ecossistemas aquáticos contaminados por metais pesados. Viçosa: Universidade Federal de Viçosa, Departamento de Solos - Sociedade Brasileira de Recuperação de Áreas Degradadas, 1998. p. 235-246.

16 FORNASIERO, R.B. Fluorides effects on Hypericum perforatum plants: first field observations. Plant Science, v. 165, p. 507-513, 2003.

17 GARG, P.; CHANDRA, P. Toxicity and accumulation of chromium in Ceratophyllum demersum L. Bull. Environ. Contam. Toxicol., v. 44, p. 473-478, 1990.

18 GAUR, J.P.; NORAHO, N.; CHAUHAN, Y.S. Relationship between heavy metal accumulation and toxicity in Spirodela polyrhiza (L.) Schleid. and Azolla pinnata R.Br. Aquatic Botany, v. 49, p.183-192, 1994. 
19 GRANATO, M. Utilização do Aguapé no tratamento de efluentes com cianetos. Rio de Janeiro: CETEM/ CNPQ, 1995. 42 p. (Série Tecnologia Ambiental).

20 GUIMARÃES, F.P. Potencial de macrófitas para remoção de arsênio e atrazine em solução aquosa. Viçosa, 2006. 72 p. Dissertação (Mestrado em Botânica) - Universidade Federal de Viçosa.

21 HITCHCOCK, A.E; ZIMMERMAN, P. M. Toxic effects of vapors of mercury and of compounds of mercury on plants. Ann. N. Y. Acad. Sci., v. 65, p.474-497, 1957.

22 HOAGLAND, D.R.; ARNON, D.I. The water-culture method for growing plants without soil. Berkeley: California Agricultural Experiment Station,1950. 37 p. (Bulletin, 347).

23 LEMOS, R.M.A.; PINTO, F.N.; GUIMARÃES, J.R.D.; BIANCHINI Jr., L.; FOSTIER, A. H.; FORTI, M. C.; MELFI, J. A. Macrófitas aquáticas e sedimentos como indicadores de $\mathrm{Hg}$ a jusante do garimpo do Tartarugalzinho, AP, Brasil. In: SIMPÓSIO DE ECOSSISTEMAS BRASILEIROS, 4., Águas de Lindóia, 1998. Anais ... São Paulo: Academia de Ciências do Estado de São Paulo, 1998. p. 440-451.

24 MASCARENHAS, A.F.S.; BRABO, E.S.; SILVA, A.P.; FAYAL, K.F.; JESUS, I. M.; SANTOS, E.C.O. Avaliação da concentração de mercúrio em sedimentos e material particulado no rio Acre, estado do Acre, Brasil. Acta Amazônica, v. 34, n. 1, p. 61-68, 2004.

25 MATAGI, S.V.; SWAI, D.; MUGABE, R. A review of heavy metal removal mechanisms in wetlands. African Journal of Tropical Hydrobiology and Fisheries, v. 8, p. 23-35, 1998.

26 NEDLKOSKA, T.V.; DORAN, P.M. Characteristics of heavy metal uptake by plants species with potential for phytoremediation and phytomining. Minerals Engineering, v. 13, n. 5, p. 549-561, 2000.

27 OLIVEIRA, J.A.; CAMBRAIA, J.; OLIVA, M.A.; JORDÃO, C.P. Absorção e acúmulo de cádmio e seus efeitos sobre o crescimento relativo de plantas de aguapé e de salvínia. Revista Brasileira de Fisiologia Vegetal, v. 13, p. 329-341, 2001.

28 PEDRALLI, G. Macrófitas aquáticas como bioindicadoras da qualidade da água: alternativas para os usos múltiplos de reservatórios. In: THOMAZ, S. M.; BINI, L. M. (Eds.). Ecologia e manejo de macrófitas aquáticas. Maringá: Universidade Estadual de Maringá. 2003. p. 171-188.

29 PFEIFFER, W. C.; FISZMAN, M.; MALM, O.; AZCUE, J. M. Heavy metal pollution in the Paraíba do Sul River, Brasil. Sci. Tot. Environ., v. 58, p. 73-79, 1986.

30 POTT, V. J.; POTT, A. Potencial de uso das plantas aquáticas na despoluição da água. Campo Grande: Embrapa Gado de Corte, 2002. 25 p.

31 RODRIGUES, A. P. C.; CASTILHOS, Z. C.; SILVA, L. C. C. P.; ALBUQUERQUE, C.; INÁCIO, A. F.; AGOSTINI, L. N.; LINDE, A. R.; ALMOSNY, N. Bioavaliação de risco em ecossistemas aquáticos contaminados por mercúrio. Estudo de caso: Netuma barba, Ilha das Enxadas, Baia de Guanabara, RJ. In: CONGRESSO DE ECOLOGIA DO BRASIL, 6., Fortaleza, 2003. Anais... Fortaleza, CE: Ed. da Universidade Federal do Ceará, 2003.

32 SCHNEIDER, I. A. H.; RUBIO, J. Plantas Aquáticas: adsorventes naturais para a mehoria da qualidade das águas. Porto Alegre: UFRGS, 2003. 16 p. Prêmio Jovem Cientista - Água: Fonte de Vida.

33 SILVA, L. C.; AZEVEDO, A. A.; SILVA, E. A. M.; OLIVA, M. A. Flúor em chuva simulada: sintomatologia e feitos sobre a estrutura foliar e o crescimento de plantas arbóreas. Revista Brasil. Bot., São Paulo, v. 23 , n. 4, p. 385-393, dez. 2000.

34 SUN, E. J.; SU, H. J. Fluoride injury to rice plants caused by air pollution emitted from ceramic and brick factories. Environ. Pollut. Ser. A, v. 37, p. 335-342, 1985.

35 VIEIRA, J. L. F.; PASSARELLI, M. M. Determinação de mercúrio total em amostras de água, sedimentos e sólidos em suspenção de corpos aquáticos por espectrofotometria de absorção atômica com gerador de vapor a frio. Revista Saúde Pública, v. 30, n. 3, p. 256-60, 1996.

36 WEINSTEIN, L. H. Fluoride and plant life. J. Occup. Med., v. 9, n. 1, p. 49-78, 1977.

37 WHO. World Health Organization. Mercury - environmental aspects. Geneva, 1989. 115 p. (Environmental Health Criteria, 86). 